\title{
A fisiologia e seu discurso
}

Physiology and its own discourse

\author{
Isabel Coelho Fragelli \\ Universidade de São Paulo
}

\section{RESUMO}

Trata-se de examinar, a partir do livro La physiologie des Lumières, de François Duchesneau, a inserção da fisiologia no quadro da filosofia moderna, em especial no período de transição do paradigma cartesiano para o newtoniano, na virada do século XVII para o XVIII.

\section{PALAVRAS-ChAVE}

Fisiologia, Racionalismo, Empirismo, Transcendental.

\section{ABSTRACT}

The aim of the article is to study the ways in which Physiology as a science came to have a philosophical dimension. This happened in the passage from the XVII ${ }^{\text {th }}$ to the XVIII ${ }^{\text {th }}$ Century, when philosophy itself shifted from a Cartesian to a Newtonian paradigma. Our main source in this article will be François Duchesneau's La phyisiologie des Lumières.

\section{KEY WORDS}

Physiology, Rationalism, Empiricism, Transcendental. 
O estudo de François Duchesneau, La physiologie des Lumières, publicado pela primeira vez em I982 e reeditado em 2012 (Duchesneau 20I2), tornou-se um clássico, e por boas razões. É um livro que se insere em uma linhagem inaugurada por Georges Canguilhem, que, em La formation du concept de réflexe (1957; 1979), demonstrou a imbricação entre metafísica e fisiologia na época moderna. Mas, enquanto Canguilhem centrava seus estudos no paradigma cartesiano, mostrando como a fisiologia, que estuda as operaçóes do corpo humano, se enquadra no esquema dualista de separação entre corpo e alma, substância extensa e substância pensante, o foco de Duchesneau recai na fisiologia sob o impacto da ciência newtoniana, quando a questão cartesiana é relegada a segundo plano e dá lugar a considerações de método que dão origem a novos modelos de compreensão dos seres organizados.

Apesar das diferenças de concepção e de método que separam Duchesneau de Canguilhem, pode-se dizer que La physiologie des Lumières põe ao leitor de filosofia uma dificuldade tal como a oferecida por La formation du concept de réflexe: o fato de nele serem abordados principalmente os textos dos doutos da época - médicos, anatomistas, fisiologistas, embriologistas etc. - exige do leitor, em diversos momentos, um conhecimento mínimo do vocabulário técnico das ciências biológicas. É certo, porém, que essa dificuldade não o impedirá de compreender o caráter essencialmente filosófico de toda problematização teórica da vida, tal como ela se deu ao longo do século xviII. Nesse sentido, devemos ressaltar que o objetivo do autor não é exatamente o de realizar uma genealogia do conceito moderno da fisiologia como ciência, mas o de compreender quais foram as "condições racionais" que tornaram possível, na época, a estruturação de uma ciência particular e autônoma dos fenômenos fisiológicos. Para isso, seria necessário investigar, em primeiro lugar, o modo como o objeto desta ciência (a saber, os corpos organizados) se constituiu enquanto tal e, em segundo, quais foram e como se desenvolveram os diversos modelos teóricos que deveriam explicá-lo. De acordo com Duchesneau, a elaboração desses modelos dependia da formalização de uma metodologia experimental adequada à especificidade do objeto e, ao mesmo tempo, de um questionamento fundamental a respeito dos limites da função especulativa da metafísica.

Com base em uma perspectiva histórica, é preciso observar as importantes transformações pelas quais o cenário teórico-científico passou ao longo desse período inicial da Modernidade. Se a fisiologia do século XVII não era ainda uma ciência inequivocamente distinta da física (pois, nesse momento, "nenhuma fronteira epistemológica precisa separava a parte da física que se ocupava das realidades inorgânicas daquela que se ocupava das realidades orgânicas"), agora, 
no século das Luzes, o domínio das ciências exatas no interior do universo natural passa a ter suas fronteiras delineadas de um modo cada vez mais preciso (Duchesneau 20I2, p. I2). Segundo o autor, esse período será marcado por uma concepção empirista do saber teórico e, principalmente no que diz respeito à biologia, por uma consequente recusa do racionalismo cartesiano, uma vez que a compreensão dos fenômenos correspondentes à experiência do vivo se mostrará cada vez mais hostil às explicaçôes fundadas em hipóteses mecanicistas estabelecidas a priori. Entre esses fenômenos, o famoso pólipo de água doce (descoberto por volta de 1740 pelo naturalista suíço A. Trembley), a geração de seres híbridos e os monstros serviram de argumentos privilegiados para a crítica do mecanicismo tanto na fisiologia, quanto na embriologia. Essa crítica foi decisiva para o próprio processo de determinação da especificidade do objeto dessas ciências, e não por acaso as teorias vitalistas e organicistas foram predominantes nas últimas décadas do século XVIII; contudo, ela não deveria excluir por completo toda explicação mecânica da compreensão dos fenômenos vitais, mas apenas delimitar seu papel no interior de um saber determinado da matéria orgânica. Como explica Duchesneau, a partir dos anos 50, a ambiguidade entre o objeto da física e objeto da fisiologia não mais se justifica: com a publicação dos Elementos da fisiologia do corpo humano (1757), de A. von Haller, os fenômenos fisiológicos passariam a ser compreendidos segundo uma ordem própria e particular, paralela à ordem dos fenômenos estabelecida e explicada pelas leis da física.

É nesse sentido que La physiologie des Lumières atribui ao século das Luzes o mérito de ter operado a "transição das teorias do vivo à teoria fisiológica", e de ter, com isso, preparado o terreno para a verdadeira revolução científica da biologia, que se daria somente na passagem para século seguinte (Duchesneau 20I2, p. 685). Nessa transição, por um lado, é o conceito de organismo que permite a emergência da fisiologia como um saber autônomo - e, por outro, de um modo recíproco, é a própria delimitação teórica de um certo campo fenomênico que permite a determinação deste conceito de organismo, bem como das noções por ele mobilizadas (como as de ordem, função, órgão etc.). Por esse motivo, é possível afirmar que a passagem concretizada posteriormente, da história natural para a biologia - ou, como esclarece o autor, "de um saber descritivo e classificatório dos caracteres morfológicos para uma teoria dos mecanismos de funcionamento fundada experimentalmente" (Ibid., p. I5) —, será articulada por uma noção de organização que já começava a emergir nas teorias fisiológicas do século XVIII.

De um modo geral, a fisiologia das Luzes rejeitará os modelos explicativos oriundos da física cartesiana (para a qual não existem organismos, propriamente, já que a vida é reduzida ao mero desenrolar de processos mecânicos) e buscará 
principalmente em Newton, embora também em Leibniz, alguns dos elementos necessários para a elaboração de novos modelos. Mas não devemos supor que se tenha apenas substituído um paradigma por outro: enquanto Descartes, tal como dissemos mais acima, constrói uma representação metafísica de sua cosmologia mecanicista a partir de hipóteses estabelecidas a priori, Newton, ao contrário, formaliza a aplicação da matemática aos fenômenos naturais a partir de uma metodologia científica eminentemente empirista e indutiva, deixando de lado, ao menos enquanto cientista, a determinação das causas e das essências pelas vias da metafísica.

Deve-se notar, contudo, que a fisiologia do século XvinI extraiu diversas representações analógicas dos sistemas tanto de Newton quanto de Leibniz: os esquemas teóricos oferecidos pela monadologia e pela gravitação universal, por exemplo, foram amplamente empregados pelos naturalistas da época em seus modelos de interpretação dos fenômenos orgânicos. Entretanto, no caso de Newton, mais importante do que observar o emprego analógico dos modelos de sua teoria física é compreender de que maneira sua metodologia, ao ser importada para uma investigação particular da matéria orgânica, contribuiu para a própria delimitação do domínio específico da ciência fisiológica (mesmo quando se tratou de demonstrar que o objeto desta ciência é irredutível às leis mecânicas).

Ao longo de toda a investigação desenvolvida em La Physiologie des Lumières, Duchesneau ressalta a importância da função epistemológica dos "inconnues explicatives" para as formulações teóricas da teoria fisiológica nascente, mostrando que, em diversos momentos, fez-se um uso regulativo de elementos "desconhecidos" para que se pudesse explicar os fenômenos observados nos organismos. Para exemplificar, assim como Newton define a lei da gravidade sem determinar o estatuto ontológico desta força, assim também Buffon pode explicar a funcionalidade das "forças penetrantes", Blumenbach a das "forças vitais" e Haller a da irritabilidade da fibra sem, contudo, determinarem o que são esses elementos ou quais seriam as suas causas (Hall 1968; Gaskin 1967, cap. 7). Ainda que seja demasiado ousado, como diz o autor de La Physiologie des Lumières, afirmar que a fisiologia dos século xvıI erigiu-se com base em um "paradigma" newtoniano, a apropriação de sua metodologia por parte dos naturalistas teve grande importância para elaboração do próprio discurso teórico desta ciência: nesse sentido, o uso epistemológico dos "inconnues explicatives" permite-nos, no mínimo, observar que não apenas a ciência física, mas também a biologia do século das Luzes, de um modo geral, evita recorrer às explicações metafísicas dos elementos indeterminados, ao mesmo tempo em que lida constantemente com os limites do saber empírico. Assim lemos, em uma passagem da Conclusão: "o dogma, seja ele teológico ou metafísico, não basta mais para satisfazer a exigência 
de clareza, uma vez que a própria ordem dos fenômenos delimita a problemática das operações do organismo e das leis vitais" (Duchesneau 20I2, p. 696).

Ora, se o dogma metafísico já não basta, então é preciso que uma nova heurística seja inventada para a história natural. Além disso, quando se admite que os fenômenos vitais não podem ser reduzidos às leis mecânicas, então essa ciência terá que enfrentar uma dificuldade dupla, a saber: como é possível construir um discurso teórico a respeito dos fenômenos vitais com base na experiência e, portanto sem recorrer à metafísica, mas tampouco servindo-se das explicações matemáticas? É verdade que a experiência desses fenômenos foi muito tateante neste período, motivo pelo qual houve uma enorme proliferação das mais diversas e singulares teorias biológicas que, muitas vezes, divergiam umas das outras e até mesmo se contradiziam (Pichot 1993, p. 392); mas a razão disso não é tanto a de que talvez faltassem recursos materiais para aprimorar a observação empírica, mas a de que se estava buscando, através da própria experiência, os conceitos, a linguagem, os métodos, em suma, uma "arte de descobrir" que fosse capaz de determinar de algum modo esse objeto muito particular que é a vida. É justamente por isso, reiterando o que dissemos mais acima, que o processo de identificação desse campo específico de fenômenos (o dos fenômenos vitais, ou orgânicos) acompanha, numa relação de determinação recíproca, a própria elaboração conceitual das teorias:

Em nossa opinião, nenhum conceito significa a priori o esquema da organização vital se admitirmos que ele se situa, de imediato, em uma relação analógica com as condições estruturais e com as "disposiçōes" do corpo orgânico e que é elaborado no quadro de uma teoria empiricamente fundada. Os conceitos que designam o esquema da organização vital são, portanto, também eles, aquisiçóes da teoria, logo da experiência, mas conforme o momento racional de uma análise da ordem funcional. (Ibid., p. 698)

No percurso traçado por Duchesneau, Stahl é o primeiro naturalista a romper com a economia mecanicista, por ter julgado que os processos orgânicos não poderiam ser compreendidos senão com base em uma ordem teleológica. Mas, para inserir essa ordem no processo de composição orgânica, Stahl recorre a um artifício metafísico, que consiste em atribuir à alma, isto é, a um princípio atuante inteligível, exterior à própria natureza, a função organizadora da matéria, cujo logos finalista é, em última instância, determinado pelo Criador. Nessa primeira metade do século XVIII, foram ainda os grandes, e últimos, sistemas mecanicistas, tais como os de Hoffmann e de Boerhaave, que contestaram o animismo stahliano; entretanto, ressalta Duchesneau, o "mecanismo" já operava aqui como uma 
espécie de conceito regulador. (Ibid., p. 696) No caso de Hoffmann, a ordem dos fenômenos fisiológicos deveria ser deduzida a partir de um modelo mecanicista da estrutura anatômica, por meio de analogias experimentais. Sua medicina racional rejeita as suposições hipotéticas e procura inferir as leis mecânicas da natureza orgânica a partir da experiência, porém sempre referindo-as aos princípios gerais da mecânica estabelecidos a priori pela razão. Ele critica Stahl e outros autores, em particular aqueles que seguiram a linha da medicina galênica, por terem recorrido a certas entidades "psicológicas" para explicar os processos orgânicos. Essa tendência é curiosamente qualificada, por ele, como nominalista: "O nominalismo, nesse sentido", explica Duchesneau,

Consistia em substituir a explicação baseada em causas próximas, "sensíveis e que a razão poderia apreender", por forças espirituais e morais, por entidades dotadas de uma faculdade intrínseca de consciência e de razão, que valiam pouco mais do que simples nomes destinados a recobrir um vazio de conhecimento. (Ibid., p. 74)

Hoffmann opõe à ciência assim concebida uma ciência "real", capaz de inferir as causas próximas a partir da análise dos efeitos. Seu sistema, porém, entra em contradição no momento em que ele precisa explicar a própria "organicidade" dos corpos vivos. Inspirado por Leibniz, ele não compreende a matéria como uma instância meramente passiva (e, com isso, contrapõe-se a Stahl, para quem a matéria serve como uma espécie de instrumento para a atuação da alma), mas atribui a ela uma capacidade dinâmica - o que produz uma série de ambiguidades em sua teoria. Para explicar o processo de estruturação arquitetônica dos organismos, ele acaba inserindo, em seu sistema, uma espécie de princípio organizador, concebido na forma de uma força motriz nervosa [vis motrix nervea] presente em um substrato específico, o fluido nervoso. A função arquitetônica atribuída a essa força certamente recoloca, para a análise fisiológica, o problema da teleologia que Stahl identifica e procura solucionar a partir dos princípios da teoria animista. Em última instância, como diz Duchesneau, a hipótese de Hoffmann chega a ser "quase mítica" e póe em cheque novamente o argumento da fisiologia mecanicista (Ibid., p. IO5).

Boerhaave, por sua vez, produz uma versão menos rica do mecanicismo (ou, se preferirmos, do iatromecanicismo), se comparada com a de Hoffmann, e tampouco desprovida de contradições; contudo, ela contribuiu de modo significativo para transformar o método da ciência fisiológica deste período. Entre os naturalistas pré-hallerianos, foi ele, afinal, um dos primeiros a incorporar explicitamente a epistemologia newtoniana e a fazer dela um emprego muito particular na fisiologia, o que trouxe diversas consequências para o desenvolvimento ulterior desta ciência. 
(Ibid., pp. I74-I75) Tendo também adotado a metodologia empirista, Boerhaave critica abertamente os fisiólogos cartesianos pelo fato de pretenderem realizar "uma aplicação a priori do método mecanicista na medicina”, e julga que a fisiologia deveria alcançar a explicação dos processos orgânicos a partir de conhecimentos obtidos mediante a experiência - logo, a posteriori. Nesse sentido, a ciência deveria partir de um "cálculo dos efeitos" para, então, aceder ao modelo mecânico da organização corporal, deixando-se de lado toda e qualquer investigação a respeito da natureza dos agentes causais, isto é, dos elementos "desconhecidos" e "inefáveis" que ultrapassam o domínio da observação empírica (Ibid., p. 177).

Ora, todo o problema da teoria boerhaaviana, tal como Duchesneau observa, reside no fato de que ela realiza precisamente o contrário do que ambiciona. Ao pretender explicar os fenômenos fisiológicos a partir da experiência e com o auxílio de conceitos próprios da teoria mecânica, Boerhaave acaba, contudo, realizando uma sistematização a priori da ordem dos efeitos que conduz a uma aplicação "adventícia" do modelo mecanicista. Em última análise, os elementos desconhecidos (“inconnues explicatives”), aos quais deveria ser atribuída uma função meramente especulativa, transformam-se em postulados que garantem a ordenação dos fenômenos segundo a analogia com aquele modelo. Tal como lemos em La Physiologie des Lumières, Boerhaave

Postula uma metodologia mecanicista fundada na análise dos dados empíricos por meio de conceitos da mecânica, mas a tendência que se instaura na aplicação diverge deste objetivo: trata-se, pois, de aplicar um reducionismo a priori que difere muito pouco das práticas teórica próprias dos iatromecanicistas discípulos de Descartes. (Duchesneau 20I2, p. I8I)

A mesma defesa de um empirismo "estrito" e a forte inspiração no método newtoniano de um modo geral encontramos também em Haller, o grande fisiólogo do século XviII que, por sinal, foi discípulo de Boerhaave. Quanto ao emprego das hipóteses, Haller atribui a elas um certo uso funcional de extrema importância para a construção de novos conhecimentos em uma ciência empiricamente fundada. Embora também rejeite as hipóteses a priori empregadas por Descartes - as quais, para ele, não passam de "frutos de uma arquitetônica imaginária na explicação dos fenômenos naturais" (Ibid., p. 20I) - acredita que se elas forem elaboradas a partir de dados empíricos, possibilitando uma transição provisória do desconhecido para o conhecido, mesmo que não possam ser consideradas verdadeiras, mas apenas verossímeis, podem ser de grande utilidade para o cientista (Roe I98I, p. IOO). Com efeito, o modo como Haller também recorre à função epistemológica dos "inconnues explicatives" está intimamente associado à sua concepção do uso das 
hipóteses: quando devidamente circunscrito mediante uma análise atenta dos dados empíricos, o "desconhecido" pode ser apontado como uma hipótese provável, e pode, inclusive, ser nomeado no interior da teoria. É assim que Haller, apesar de seu empirismo observacional rigoroso, não permite que os limites do saber empírico "reduzam ao silêncio a voz que tende naturalmente à sistematização teórica" (Ibid., p. 20I).

Com base nesses pressupostos metodológicos, Haller desenvolve sua famosa teoria da irritabilidade da fibra, que sem dúvida consiste em sua contribuição de maior importância para a definitiva transformação da fisiologia em uma ciência autônoma. Como mostra Duchesneau, diversos estudos sobre as propriedades da fibra já haviam sido esboçados pelo naturalista italiano G. Baglivi, porém é Haller que confere a eles um enquadramento teórico mais completo e original. Para o cientista belga, a "irritabilidade" é uma propriedade específica das fibras musculares (e não das fibras nervosas, que possuem a "sensibilidade"), devido à qual elas contraem quando estimuladas por algum elemento externo (e, por isso, está associada à elasticidade). Isso se observa, por exemplo, nos movimentos cardíacos de sístole e diástole, nos movimentos peristáltico dos intestinos etc. Haller acredita que a irritabilidade seja uma força, tal como as outras forças físicas da natureza que, contudo, pertence a uma estrutura orgânica específica: a fibra muscular animal. Ora, por que motivo uma tal estrutura é dotada de uma determinada força, eis o que não pode ser explicado pelo cientista da natureza. Sabe-se, a partir da observação dos fenômenos associados à fibra muscular, que elas contraem do modo acima mencionado, e a análise dos dados dessa observação são suficientes para que se possa postular que tais fenômenos são efeitos de uma força particular dessa estrutura material. A verdadeira causa desta força, contudo, permanece desconhecida: "As realidades materiais são dotadas de forças, sem que seja possível elucidar positivamente o estatuto ontológico dessas forças, a não ser afirmando que elas devem vir de uma fonte extrínseca à matéria e, por conseguinte, do próprio Deus" (Ibid., p. 4I3).

Como se pode notar, o estudo anatômico de uma determinada estrutura corporal conduz Haller à descoberta de um movimento essencial para as funções vitais dos organismos. A fisiologia não deve consistir em outra coisa, portanto, senão na investigação daqueles movimentos que podem ser denominados movimentos vitais: ela é a "anatomia em movimento", anatomia animata, como ele afirma em uma passagem célebre da obra Primae lineae Physiologiae (1747) (Canguilhem 2015, p. 227). Aos movimentos vitais estão associadas as diversas funçôes orgânicas, cuja determinação a fisiologia poderá realizar, na verdade, não apenas com base em um exame minucioso das partes (i.e., das estruturas particulares) e de suas 
respectivas atividades, mas a partir de uma análise da estruturação global do organismo. É aqui, porém, que Haller enfrenta uma dificuldade particular: visto que ele recusa toda forma de ordenação a priori dos fenômenos, seja com base em generalizações abstratas, seja por meio de analogias hipotéticas, como lhe será possível compreender a articulação das funções vitais a partir de uma perspectiva global do corpo organizado? A teoria da irritabilidade, por si só, certamente não permite que as funções orgânicas sejam articuladas em um plano geral, já que ele não compreende essa força como um princípio estruturante. A dificuldade permanece, assim, sem uma clara resolução no interior de sua teoria fisiológica:

[Haller] não pode escapar à interrogação que se volta sobre o modo de agenciamento funcional e sobre o sistema das ações orgânicas. A história natural das partes, somente, não pode fornecer-lhe qualquer instrumento conceitual de análise no que concerne tanto às constantes funcionais, quanto à lei de integração das estruturas complexas. [...] Seu problema, nós o assinalamos, é o de conceber a integração dos dispositivos orgânicos elementares de modo a explicar a razão das funções globais. (Ibid., p. 346)

Graças às influências de Boerhaave, a teoria halleriana desenvolve-se ainda no interior do quadro das concepções mecanicistas; porém, na medida em que Haller procurar explicar a integração estrutural a partir da composição e do "ajuste" das partes (ou de determinadas microestruturas orgânicas), sua compreensão do organismo carece da representação sistemática que a referência analógica e a priori aos modelos mecânicos oferecia às teorias iatromecanicistas. Além disso, a importação dos modelos mecânicos da física newtoniana para explicar a atuação das forças encontradas na matéria orgânica, tais como a irritabilidade e a sensibilidade, é bastante problemática: como o próprio Haller observa, os movimentos vitais se dão segundo leis muito particulares que, no geral, escapam

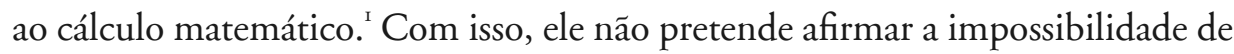
explicar os fenômenos fisiológicos a partir das leis mecânicas, mas apenas dizer que, para alcançar esse conhecimento, será necessário investigar esses fenômenos

I Eis a passagem dos Elementa physiologiae corporis humani (I757) citada por Duchesneau: "Dans l'animal, de nombreuses machines sont tout à fait étrangères aux lois mécaniques communes; de petites causes provoquent de grand mouvements; la vitesse des humeurs est peu diminuée par des causes qui, suivant les lois reçues, devraient la rompre; des mouvements s'insinuent par des causes profondément inconnues; des fibres débiles produisent des mouvements violents, des raccourcissements de fibres se produisent, dépassant tout le calcul, etc”. (Ibid., p. 199). 
em sua especificidade e a partir da observação minuciosa dos dados empíricos. Em resumo, por estar associada de um modo frágil ao modelo mecânico e por abrir o caminho para uma ciência particular dos fenômenos vitais, a teoria da irritabilidade acaba colocando em cheque o sistema mecanicista, embora Haller pretendesse conservar seus princípios.

As alternativas às ambiguidades presentes na teoria halleriana serão extraídas principalmente a partir do estudo dos fenômenos da geração, motivo pelo qual se darão mais no domínio da embriologia do que no da fisiologia. Uma vez circunscrito o campo dos fenômenos vitais por meio de uma análise específica dos movimentos fisiológicos, o conceito de vida poderá, enfim, assumir um lugar legítimo no interior das teorias biológicas. A partir da segunda metade do século XVIII, as teses vitalistas dominarão o cenário da história natural e se desenvolverão de maneiras distintas, como nos mostra Duchesneau, tanto no território alemão, quanto no francês.

O debate a respeito do problema da geração desenvolveu-se em torno de duas teorias principais: a da pré-formação e a da epigênese. Ao longo de sua trajetória, Haller mudou diversas vezes de opinião: defendeu, inicialmente, uma versão animaculista da teoria da pré-formação; em seguida, após tomar conhecimento da descoberta do pólipo de água doce por A. Trembley, tornou-se epigeneticista; e, por fim, retornou à teoria pré-formacionista, agora sob a perspectiva ovista. Isso de algum modo sugere sua dificuldade de assumir um modelo teórico que permita explicar o processo de formação dos corpos orgânicos, e não o funcionamento de um organismo já formado (o qual consiste, propriamente, no objeto da fisiologia). De todo modo, a adesão prioritária de Haller ao modelo pré-formacionista é coerente tanto com sua perspectiva metodológica, quanto com seu esforço de conservar os princípios da fisiologia mecânica, considerando-se, afinal, que o vitalismo deste período recorre constantemente a diversas "hipóteses" para fundamentar a explicação epigenética.

Mas em que consistem essas tais "hipóteses" vitalistas? Sem deixar de ressaltar as ambiguidades também presentes nos debates em torno da epigênese, Duchesneau aponta constantemente para o caráter regulador que os princípios ou forças vitais assumiram nos diferentes projetos vitalistas. A vis essentialis de C. F. Wolff e o Bildungstrieb de Blumenbach, por exemplo, não deixam de ser princípios estabelecidos a partir da observação de seus efeitos nos corpos organizados: o elemento desconhecido e irredutível às explicações mecânicas deixa de ser visto como uma mera hipótese fantasiosa para ser, agora, circunscrito e nomeado no interior do discurso teórico, de modo a assumir uma função epistemológica essencial para a explicação dos fenômenos da geração baseada na perspectiva epigenética. Pode-se 
dizer que, de um modo geral, não se procurou determinar o estatuto ontológico dos princípios de organização vital que foram propostos (uma vez que a metodologia empregada é, também aqui, uma metodologia empirista), mas apenas delimitar o lugar ocupado pelo elemento "inconnu" presente na matéria orgânica, a fim não apenas de conhecê-lo, por assim dizer, "por aproximação", como também de compreender os fenômenos que lhe são adjacentes, sem que seja necessário rejeitar por completo as explicações mecânicas.

Entre os alemães, é Wolff quem primeiro realiza uma reabilitação consistente (i.e., bem argumentada e baseada na experiência) da teoria epigenética no domínio da embriologia. A vis essentialis é por ele definida como uma força de nutrição, análoga à que se observa na formação dos cristais, porém mais complexa, uma vez que não realiza uma mera "justaposição", mas sim uma "assimilação íntima" dos materiais durante o processo de formação dos organismos vivos. Essa força, contudo, não exerce a função de um princípio arquitetônico de estruturação orgânica: ela é, tal como nos explica Duchesneau, uma "força material", capaz de operar

Uma função discriminante entre os elementos materiais com vistas à formação, ou, mais precisamente, à estruturação orgânica, mas esse "com vistas a" não pode ser nada além de uma fórmula metafórica, e a função discriminante é comparável às "afinidades químicas" que devemos associar aos fenômenos mecânicos dependentes da relação atração-repulsão. (Duchesneau 20I2, p. 455)

Ora, de que modo seria possível explicar, com base em uma tal força material de nutrição, a ordem teleológica que se observa no desenvolvimento da forma dos corpos orgânicos? É esta a principal questão que Blumenbach coloca à teoria de Wolff - a quem, contudo, ele provavelmente deve a concepção geral do esquema de desenvolvimento epigenético que fundamenta sua crítica ao pré-formacionismo halleriano. (Ibid., p. 493) Em seu sistema, Blumenbach não deixa de atribuir à vis essentialis wolffiana um papel importante para o processo de formação dos organismos; mas, segundo ele, essa força precisa ser compreendida como uma simples força mecânica que, assim como as outras forças mecânicas atuantes nos organismos, deverá estar subordinada a um princípio capaz de exercer uma função arquitetônica no processo de organização da matéria. Este princípio, que Blumenbach nomeou Bildungstrieb, ou impulso de formação (Bildung = forma, ou formação; Trieb = impulso), é, "ao mesmo tempo, agente de estruturação e razão suficiente natural da ordem resultante" (muito distinto, portanto, da "alma" de Stahl, que consistia em um agente de ordenação teleológica inteligível e exterior 
à natureza). Graças à sua atividade, a formação gradual dos corpos orgânicos não ocorre "às cegas", mas teleologicamente, segundo uma "produção típica" da organicidade (Ibid., p. 693).

Com efeito, nas objeções de Wolff à teoria da pré-formação, já se fazia presente uma crítica à idéia de que a "razão suficiente" das formas orgânicas reside em sua própria estrutura pré-formada (Ibid., p. 495). É Blumenbach, porém, quem melhor resolve o problema da teleologia (tal como já havia sido identificado por Stahl) no interior da concepção epigenética da ciência embriológica, recorrendo não a uma solução de caráter dogmático-metafísico, mas a uma "hipótese" verossímil extraída a partir da experiência, cuja função epistemológica se dá bem ao modo dos "inconnues explicatives" newtonianos. "De acordo com o modelo epistemológico fornecido por Newton”, diz Duchesneau,

As forças remetem a um arranjo dos elementos (relativamente ou absolutamente) incognoscível [inconnaissable]: donde a transposição [feita por Blumenbach] da razão suficiente de uma estrutura primordial complexa a uma "força específica", cujo estatuto não é mais redutível às condições da experiência enquanto condiçôes de possibilidade. (Ibid., p. 695)

Em outras palavras, é a própria causa dos processos epigenéticos que escapa ao conhecimento do cientista, uma vez que essa "força específica" não pode ser determinada. Seja qual for o nome que se queira dar a ela — "força", "impulso", "tendência", "esforço" etc. —, o que compete à ciência dos seres vivos é identificar os efeitos deste princípio na matéria orgânica, a fim de que a partir deles se possa inferir, tanto quanto possível, as regras ou padróes de seu modo de atuar na natureza (Blumenbach I78I, p. I2). Guardadas as devidas diferenças entre ambos os autores, também Barthez, vitalista da escola de Montpellier, atribui a seu princípio vital uma função especulativa semelhante à do Bildungstrieb de Blumenbach: independentemente da palavra que se escolha para nomear esse elemento "incognoscível", não se trata de determinar sua natureza essencial, mas de tomá-lo como um tipo de causa geral dos fenômenos vitais que apenas pode ser reconhecida por meio de seus efeitos. Assim lemos, em La Physiologie des Lumières:

2 Há controvérsias a respeito do caráter "não dogmático" do Bildungstrieb blumenbachiano. Ver a respeito Robert Richards, "Kant and Blumenbach on the Bildungstrieb: a historical misunderstanding”. In: Stud. Hist. Phil. Biol. \& Biomed. Sci., v. 3I, n. I, 200o, pp. II-32.

3 Ver a citação de Barthez em Duchesneau: "On peut donner à ces causes générales, que j'appelle expérimentales, ou qui ne sont connues que par leurs lois que donne l'expérience, les noms synonymes, et parreillement indéterminés, de principe, de puissance, de force, de faculté etc.". (Duchesneau 2012, p. 599) 
Segundo os postulados de Barthez, a noção de princípio vital deve ser interpretada conforme o estatuto das causas experimentais. Barthez toma constantemente a precaução de corrigir os intérpretes de sua doutrina que tendem a "ontologizar" o princípio. Se ele consiste na "causa que produz todos os fenômenos da vida no corpo humano", essa causa não é um princípio capaz de explicar a eficácia que determina os fenômenos, mas ela serve para designar a unidade de determinação causal desconhecida [inconnue] que supõem a ordem e a conexão dos fenômenos vitais. A noção deve orientar a verdadeira síntese explicativa dentro dos limites da experiência dos fatos. (Duchesneau 2012, p. 603).

Os principais naturalistas que vieram após Haller, portanto, buscaram maneiras de compreender os fenômenos vitais em sua especificidade de modo a não infringir os limites da experiência (já que também não abriam mão do emprego rigoroso de uma metodologia empirista). No momento em que os princípios vitais (i.e. as causas desses fenômenos) passam a ser reconhecidos e "nomeados", sem serem, por isso, tratados como objetos em si mesmos cognoscíveis, o conceito de vida assume um lugar legítimo no interior do discurso teórico da ciência natural. A vida é, com efeito, aquilo que reside precisamente na "fronteira especulativa" de nosso saber teórico a respeito da natureza, e o reconhecimento dos limites da experiência não deve impedir que ela seja tomada como uma "hipótese" verossímil, ou ao menos possível, da explicação de certos fenômenos observados pelo cientista.

Nesse sentido, não é por acaso que Duchesneau encerra seu livro com uma “reflexão kantiana”, extraída do $₫ 80$ da Crítica da Faculdade de Julgar, que possui o seguinte subtítulo: "Da subordinação necessária do princípio do mecanismo ao princípio teleológico na explicação de uma coisa como fim da natureza":

Para, pois, que o pesquisador da natureza não trabalhe inteiramente em vão, ele tem de sempre fundar o julgamento das coisas cujo conceito como fins da natureza está firmemente estabelecido (seres organizados) em alguma organização originária, a qual, por seu turno, emprega aquele mesmo mecanismo para produzir outras formas organizadas, ou transformar as suas em novas figuras (que, no entanto, sempre se senguem daquele fim e em conformidade com ele). (Kant 2016, p. 315)

Este último parágrafo talvez nos leve a pensar que o percurso de La Physiologie des Lumières está, de algum modo, submetido a uma perspectiva kantiana. Como vimos, Duchesneau associa o nascimento da fisiologia como ciência, bem como seus avanços ao longo do período das Luzes, ao desenvolvimento de um modo 
"regulativo" (termo que ele emprega com frequência) de empregar conceitos, modelos e esquemas no interior do discurso científico a respeito dos fenômenos fisiológicos. Mas não se trata, aqui, de argumentar contra ou a favor desse suposto kantismo da obra: independentemente disso, o livro nos mostra que o próprio modo de teorizar os fenômenos fisiológicos, tal como proposto pela filosofia crítica, já está presente, ainda que de maneira muito diversificada, cheia de ambiguidades, limites e, às vezes, pouco sistematizada, nas teorias dos diversos naturalistas do século XviII. Desse modo, talvez não seja demasiado ousado supormos que o sistema de Kant deve, também a eles, em alguma medida, seja a sua concepção dos "limites da experiência possível", seja a do uso regulativo dos conceitos, no que diz respeito às ciências da vida. Evidentemente, não podemos negar que o projeto crítico significa um momento decisivo da constituição do saber sobre a vida e os organismos no século xviII; mas talvez isso não se dê tanto devido ao modo como Kant identifica o lugar problemático desses temas para o conhecimento, mas principalmente pelo fato dele ter encontrado uma maneira de definir e unificar, no interior de um sistema geral da ciência da natureza, o próprio discurso teóricofilosófico para compreendê-los.

\section{Referências bibliográficas}

Blumenbach, J. F. Über den Bildungstrieb und das Zeugungsgeschäfte. Göttingen: J. C. Dietrich, I78I.

Canguilhem, G. La formation du concept de réflexe aux XVIIe et XVIIIe siècles. $2^{\mathrm{a}}$ edição. Paris: Vrin, 1977. Etudes d'histoire et de philosophie des sciences. Paris: Vrin, 2015.

Duchesneau, F. La Physiologie des Lumières. Empirisme, modèles et theories. Paris: Classiques Garnier, 2012.

Gasking, E. Investigations into Generation, 1651-1828. Baltimore: Johns Hopkins Press, 1967.

Hall, T. S. "On Biological Analogs of Newtonian Paradigms". In: Philosophy of Science, v. 35, n. I, I968, pp. 6-27.

Haller, A. Dissertation sur les parties irritables et sensibles des animaux. Tradução M. Tissot. Lausanne: M. M. Bousquet, I755.

Ріснот, A. Histoire de la notion de vie. Paris: Gallimard, 1993.

Richards, R. "Kant and Blumenbach on the Bildungstrieb: a historical misunderstanding". In: Stud. Hist. Phil. Biol. \& Biomed. Sci., v. 3I, n. I, 2000, pp. II-32. 
Roe, S. Matter, Life and Generation. Cambridge: University Press, I98I.

Stahl/Leibniz. Controverse sur la vie, l'organisme et le mixte. Paris: Vrin, 2004.

WolfF. C. F. Theorie von der Generation. Berlin, I764. 